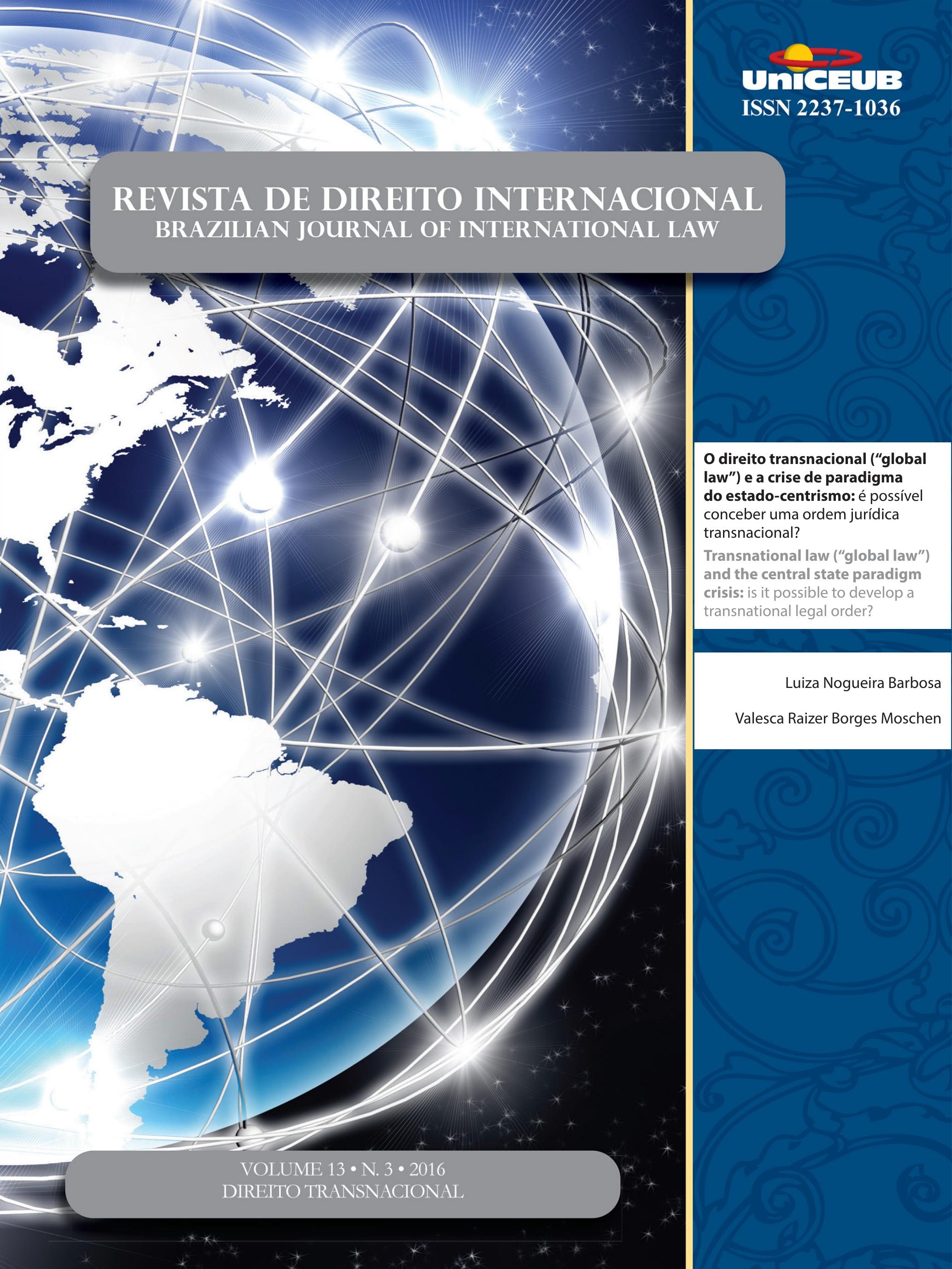


Crônicas da ATUALIdAde do direito internacional .................................................. 2

I. Dossiê Temático: Direito Transnacional .........................................................15

EDITORIAL: O Direito Transnacional - Circulação de normas e relações jurídicas transnacionais .......16 Priscila Pereira de Andrade

A emergênCia do direito transnacional ambiental .............................................18 Priscila Pereira de Andrade

Desafíos y RESPUESTAS TRANSNACIONALES FRENTE A LOS CRÍMENES AMBIENTALES ...............30 Rosmerlin Estupiñan-Silva

DiREITO TRANSNACIONAL E MUdANÇAS CLIMÁTICAS .50 Géraud de Lassus Saint-Geniès

Especies en movimiento: la Convención sobre el Comercio Internacional de Especies Amenazadas de Fauna y Flora Silvestres como espacio de “Encuentro” de discursos, ACTORES Y ESTRATEGIAS EN EL DERECHO AMBIENTAL TRASNACIONAL

María Valeria Berros e Dabel Leandro Franco

El carácter transnacional del Sistema comunitario de ECogestion « Eco-ManageMENT AND Audit SCHEME » (EMAS) DENTRo de LA UE y MÁs ALlÁ DE SUS Fronteras ......72 Adélie Pomade

O CONCEITO DE CONDUTA EMPRESARIAL RESPONSÁVEL À LUZ DOS ORDENAMENTOS JURÍDICOS BRASILEIRO, INTERNACIONAL E TRANSNACIONAL

Gabriel Webber Ziero

ARBITRAGEM NO DIREITO TRIBUTÁRIO INTERNACIONAL E NO DIREITO INTERNACIONAL DOS INVESTIMENTOS: UMA MANIFESTAÇÃO DO DIREITO TRANSNACIONAL

Vivian Daniele Rocha Gabriel 
O DIREITO TRIBUTÁRIO SOB UMA PERSPECTIVA TRANSNACIONAL

Franciele de Simas Estrela Borges

As Características do Direito Transnacional como Metodologia: Análise sob o enfoQue dos Aspectos Processuais da Arbitragem 126

Flávia Foz Mange

O DIREITO TRANSNACIONAL (“GLOBAL LAW") E A CRISE DE PARADIGMA DO ESTADO-CENTRISMO: É POSSÍVEL CONCEBER UMA ORDEM JURÍDICA TRANSNACIONAL? ...................................... 146

Luiza Nogueira Barbosa e Valesca Raizer Borges Moschen

TransPorte AÉREO E DIREITO TRANSNACIONAL: DA CONVERGÊNCIA À UNIFORMIDADE 160 Mickael R. Viglino

Outros Artigos. 175

O Fundo Monetário Internacional e a proteção dos direitos humanos: uma análise DO PROGRAMA DE CRESCIMENTO E REDUÇÃO DA POBREZA NO HAITI 177

Pablo Henrique Hubner de Lanna Costa e Carlos Alberto Simões de Tomaz

Um estranho no ninho? Padrões privados no Acordo de Barreiras Técnicas ao CoMÉRCIO DA OMC 192

Michelle Ratton Sanchez Badin e Marina Yoshimi Takitani

Os benefícios tributários do programa Inovar-Auto e os princípios da Nação Mais Favorecida e do Tratamento Nacional: uma análise dos argumentos dos Painéis atualmente em Curso contra o Brasil no Órgão de SoluÇão de Controvérsias da OMC . 211 Eric Moraes Castro e Silva

A ERA DA HUMANIDADE: REFLEXões PARA A HISTÓRIA DO DIREITO INTERNACIONAL 236 Henrique Weil Afonso

Precedentes vinculantes nos Estados Unidos da América e no direito brasileiro: Um ESTUDO COMPARADO 264

Patrícia Perrone Campos Mello 
IL DIRITTO AMBIENTALE SECONDO L'OTTICA DEL DIRITTO COSTITUZIONALE POSITIVO E LA RESPONSABILITÀ PER DANNI ALL'AMBIENTE NEL DIRITTO COMUNITARIO: LO STATO DELL'ARTE DEL DIRITTO AMBIENTALE COSTITUZIONALE E COMUNITARIO 287

Elcio Nacur Rezende

DA DESCONSIDERAÇÃo DA PERSONALIDADE JURÍDICA NAS RELAÇÕES CONSUMEIRISTAS BRASILEIRAS: ANÁLISE À LUZ DAS TEORIAS CLÁSSICAS

Daniel Amin Ferraz e Marcus Vinicius Silveira de Sá

ANALYSIS OF ADVANTAGES AND DISADVANTAGES OF FORUMS PRESCRIBED UNDER THE UNCLOS AND STATE PRACTICE: THE WAY AHEAD FOR INDIA ......................................................319

Vinai Kumar Singh

Do governo POR LEIS À governanÇA POR NúMERos: breve anÁlise do Trade in SERVICE AgreEMENT (TISA) ...............................................................................338 Jânia Maria Lopes Saldanha, Rafaela da Cruz Mello e Têmis Limberger

As DIRETIVAS EUROPEIAS COMO NORMA REGULADORA DO DIREITO ADMINISTRATIVO GLOBAL ..356 Alice Rocha da Silva e Ruth Maria Pereira dos Santos

O desenVolvimento da POlítica AGRícola COMUM dA UNião EUROPEIA 375 Tatiana de A. F. R. Cardoso Squeff

A imunidade de Jurisdição das organizaÇões internacionais FaCE AO Direito de aCESSO À JUSTIÇA 391

Fernanda Araújo Kallás e Caetano

O DIREITO INTERNACIONAL ENTRE O DEVER ÉTICO E A AÇÃo POLÍ́TICA: OS FUNDAMENTOS DE UM DEVER DE COOPERAÇÃO INTERNACIONAL NA FILOSOFIA POLÍTICA DE IMMANUEL KANT .405 Ademar Junior Pozzatti

EXTENSÃo E FRAGMENTAÇÃo NO CONTEXTO DA JURISDIÇÃO PENAL INTERNACIONAL .423 Marcus Vinícius Xavier de Oliveira

A DEFINiÇÃo JURÍdiCA DA "COMUNIDADE" .444 Nitish Monebhurrun, Michelle Lucas Cardoso Balbino, Fernanda Castelo Branco Araujo, Othon Pantoja, Míara Bogo Bruno e Cândida Dettenborn Nóbrega 
Comparative Study on Chinese Local Legislation of Science and Technology ProGRESS

LI Xiaoming e LI Yihan

O CONTROLE PENAL DO TRÁFICO DE PESSOAS: CONSTRUÇÃO JURÍDICA, INTERAÇÕES ORGANIZACIONAIS E COOPERAÇÃO INTERNACIONAL

Bruno Amaral Machado e Priscilla Brito Silva Vieira

Desativismo judicial: a extradição Battisti no Supremo Tribunal Federal .505 Francisco Rezek e Israel Paulino

A decisão norte-americana do Caso Myriad: novos paradigmas para a Proteção patenTÁRIA DO CÓDIGO GENÉTICO HUMANO E BIOTECNOLOGIA 514 José Carlos Vaz e Dias e Clarisse De La Cerda 


\title{
O direito transnacional ("global law") e a crise de paradigma do estado-centrismo: é possível conceber uma ordem jurídica transnacional?*
}

\author{
Characteristics of Transnational Law as \\ Transnational law ("global law") and the \\ central state paradigm crisis: is it possible to \\ develop a transnational legal order?
}

Luiza Nogueira Barbosa**

Valesca Raizer Borges Moschen***

\section{Resumo}

Com a crescente globalização e inter-relações jurídicas, sociais e econômicas para além das fronteiras estatais, surgem os denominados UNO's ("unidentified normative objects"), elaborados por diversos atores privados, mormente não estatais, que reivindicam seu reconhecimento como normas jurídicas. Nesse contexto, o conjunto dessas normas forma o direito global, ou direito transnacional, cuja possibilidade de existência tem sido alvo de ataques ceticistas, principalmente de adeptos de uma teoria monista do direito, para os quais direito e Estado tendem a ser tomados como sinônimos. $\mathrm{O}$ presente artigo tem como objetivo demonstrar que, a despeito da Teoria Monista ora consolidada entre a maioria dos juristas brasileiros, uma análise histórico-sociológica demonstra que o direito, sempre, existiu, independentemente de Estado e é essa a base pela qual se deve justificar a existência do direito transnacional. Dessa forma, assenta-se a Teoria do Pluralismo Jurídico como teoria fundamentadora para concepção do direito global. Mais adiante, demonstra o artigo a necessidade de reconstrução teórica do sistema jurídico, por meio da ruptura do paradigma do nacionalismo metodológico, uma vez que se conclui que as tentativas de teorização da legitimidade do direito global, fundadas em sistemas jurídicos estatais, estão fadadas ao fracasso. Por esse motivo, apresenta-se a solução concebida pelo professor Lars Viellechner, para o qual a legitimidade e os limites do direito transnacional encontram escopo na eficácia horizontal dos direitos fundamentais.

Palavras-chave: Direito Transnacional. Direito Internacional Privado. Global Law. Estado-centrismo. Pluralismo Jurídico Transnacional.

\section{Abstract}

The increasing and complexity of the globalization and the legal, social and economic inter-relations, beyond state boarders, emerge the denominated UNO's (unidentified normative objects), sourced by several pri- 
vate actors, mainly non-state actors, which claim their recognition as legal norms. In this context, the set of these normative objects comprise the global law, or the transnational law, which possibility of existence has been the target of skeptics attacks, mainly supporters of a monistic theory of law, for which state law and law tend to be understood as synonymous. Thus, this article aims to show that, despite the now consolidated monistic theory among most Brazilian jurists, a historical-sociological analysis shows that law has always existed, regardless of any State. This way, the theory of legal pluralism appears, with critical notes made by Gunther Teubner, as ground theory for the conception of transnational law. Further, the article demonstrates that attempts to theorize the global law legitimacy based on state legal systems (methodological nationalism) are doomed to failure, for which presents the Lars Viellechner's solution, for whom the legitimacy and limits of transnational law find scope on the horizontal effects of fundamental rights.

Key-words: Transnational law. International Private Law. Global Law. State-centrism. Transnational Legal Pluralism.

\section{INTRODUÇÃo}

Com o surgimento da globalização e das relações jurídicas e sociais cada vez mais complexas, nas quais, majoritariamente, se observa a inferência de múltiplas ordens jurídicas estatais e, por vezes, de normas não pertencentes a qualquer Estado de Direito, desestrutura-se, gradativamente, o paradigma de que a existência e aplicação do direito estariam limitadas à jurisdição de Estados-Nação.

Diferentes atores do mundo globalizado, estruturados em associações ou grupos sociais segmentados, ao realizarem suas atividades de caráter transfronteiriços e globais, têm sido cruciais para a criação de normas independentes de estímulos políticos de Estados ou grupos de união político-econômica estatais.

Nesse contexto transnacional, fora do âmbito de determinado Estado ou grupo de Estados, emerge uma incontável quantidade de objetos normativos não identificados, denominados de "UNO's" ("unidentified normative objects"), para além de qualquer soberania estatal, que demandam esclarecimento acerca de sua qualidade e natureza jurídica ${ }^{1}$.

O conjunto desses objetos normativos (ainda) não identificados, de acordo com estudiosos da filosofia e ciência do direito, formaria a "global law", ou o direito global, nascido "(...) com base nas periferias sociais, a partir das zonas de contato com outros sistemas sociais, e não no centro de instituições de Estados-nações ou de instituições internacionais" ${ }^{2}$.

A questão central que se põe é a seguinte: é possível conceber a existência de normas jurídicas não estatais emergidas além das fronteiras de um Estado soberano e deste independente? Melhor dizendo, é possível conceber a existência de uma ordem jurídica transnacional? Em caso positivo, quais são as condições para validação dessa concepção?

Hodiernamente, no mundo ocidental, há grande descrença na concepção de um sistema jurídico ou de uma ordem legal além do Estado e dele independente. Isso porque Estado e Direito são tidos como conceitos complementares, quando não são usados até mesmo como sinônimos.

Nesse contexto, a jurisdição é, tradicionalmente, concebida como prerrogativa essencial do Estado-nação e este, por sua vez, não seria possível sem a organização conferida pelo Direito. Logo, o ceticismo, quanto à transnacionalidade, é agravado por um nacionalismo metodológico, pela vinculação entre Estado e Direito, como se um não pudesse existir sem e além do outro.

Conforme será demonstrado, para compreensão e estudo do direito transnacional, faz-se necessário abandonar a ideia de que somente os Estados-Nação seriam autoridades competentes para criar, dizer e executar o direito. E isso só é possível, de fato, a partir de uma quebra de paradigma do estado-centrismo na ciência do direito.

Instaura-se, assim, na ciência jurídica, uma "Glaubenskrieg um die Transnationalisierung des Rechts"', uma guer-

1 FRYDMAN, Benoit. A pragmatic approach to global law. 2013. Disponível em: <http://ssrn.com/abstract $=2312504>$. Acesso em: 13 jan. 2016. pp. 03-04.

2 TEUBNER, Gunther. Bukowina global sobre a emergência de um pluralismo jurídico transnacional. Direito e Globalização 14, 2003. Disponível em: <http://www.unimep.br/phpg/editora/revistaspdf/ imp33art01.pdf>. Acesso em: 23 nov. 2015. p. 6.

3 TEUBNER, Gunther. Transnationales Recht: Legitimation durch horizontale Grundrechtswirkung. 2015. Disponível em: <https:// www.jura.uni-frankfurt.de/53908273/ViellechnerRezension1.pdf $>$. Acesso em: 4 jan. 2016. p. 1. 
ra de crenças sobre a transnacionalização do direito, na expressão certeira de Gunther Teubner. De um lado, os adeptos da corrente de que o direito não pode existir sem um Estado e, de outro, os partidários da teoria de que o direito prescinde qualquer Estado soberano.

Dessa forma, o presente artigo utiliza o método hipotético dedutivo para, a partir de ponderações e da apresentação da teoria insurgente no contexto atual o pluralismo jurídico transnacional - demonstrar que é possível conceber a existência de normas jurídicas transnacionais surgidas para fora das fronteiras e regulações de ordenamentos jurídicos estatais.

Em um primeiro momento, apontar-se-á a tradição do nacionalismo metodológico, até então vigente, de acordo com o qual o Estado é a única associação legítima de criação, interpretação e execução do direito.

Trazendo para o campo da ciência jurídica argumentos históricos e sociológicos, será apontada, de forma crítica, a necessidade de superação da referida tradição, com base na ideia de que o direito nunca foi monopólio do Estado e, sim, prerrogativa de diferentes associações e grupos sociais, tal como demonstra a Tradição Jurídica Ocidental.

Em um segundo momento, será destacada a crítica de Gunther Teubner, para o qual a adoção da Teoria do Pluralismo Jurídico clássico deve ser adotada com base em uma reformulação de suas concepções, fazendo-se necessário fundamentar o pluralismo não mais em grupos e comunidades, mas, sim, em discursos e redes especializadas de comunicação que surgem na esfera transnacional.

Por fim, buscar-se-á agrupar os estudos da Teoria do Pluralismo Transnacional para averiguar a possibilidade de se conceber uma ordem jurídica transnacional e, caso positiva, quais seriam seus critérios de aferição do sistema jurídico global, para o que se sugere a solução trazida pelo professor Lars Viellechner, segundo o qual a legitimidade e os limites do direito transnacional devem encontrar escopo na eficácia horizontal dos direitos fundamentais.

\section{O NACIONALISMO METOdOLÓGICO E A CRISE DE PARADIGMA DO ESTADO-CENTRISMO: ESTADO E DIREITO DEVEM SER TRATADOS COMO SINÔNIMOS?}

Uma das principais dificuldades, se não a principal, encontrada pela comunidade acadêmica para aceitação de uma ordem jurídica transnacional, se traduz no paradigma do estado-centrismo, de acordo com o qual o direito é tido como monopólio estatal.

As doutrinas baseadas no "contrato social", fundamentadoras da criação do Estado, justificam o surgimento deste na necessidade de criação de uma instituição ou de um corpo institucional garantidor da ordem e dos direitos dos seus contratantes, que passam, então, a ser cidadãos providos da suposta segurança advinda de um sistema jurídico ${ }^{4}$.

No entendimento contratualista, as sociedades são pensadas como recipientes, que surgem e são sustentadas na esfera de influência estatal ${ }^{5}$. O Estado é, portanto, o criador, controlador e, simultaneamente, garantidor das sociedades ${ }^{6}$.

Denota-se que, como bem define o sociólogo alemão Ulrich Beck, com base nessas concepções, a visão estado-centrista foi estabelecida como limite da percepção sociológica, sendo possível se falar de um nacionalismo metodológico ("methodological nationalism").

Neste contexto, é possível falar de um 'nacionalismo
metodológico', o que significam presunções
explícitas e implícitas de que o Estado-nação é o
recipiente de processos sociais, e que a nação fornece
a ordem fundamental para a análise dos processos
sociais, econômicos e políticos. É exatamente este
Estado nacional, a priori das ciências sociais, que é
cada fundamentalmente questionável no âmbito da
pluralização das fronteiras.

A partir de tal visão, o Estado passou a ser o deten-

4 Nesse sentido, citam-se os filósofos Hobbes, Locke e Rousseau. 5 Tradução livre do original: "Societies are thought as containers, which emerge and are sustained within the state's sphere of influence". BECK, Ulrich. The cosmopolitan state: redefining power in the global age. Disponível em: <https://equilibrium0.files.wordpress. com/2011/05/beck2006.pdf>. Acesso em: 26 jan. 2016. pp. 145146.

6 Das teorias contratualistas que tomam o Estado e Direito como sinônimos, excetua-se aqui a teoria de Locke, para quem seria possível se falar na existência de sociedades em estado de natureza, nas quais indivíduos poderiam reivindicar e usufruir de direitos, sem a presença de um Estado. LOCKE, John. Segundo tratado sobre o governo. In: Carta acerca tolerância; Segundo tratado sobre o governo; Ensaio acerca do entendimento humano. 2. ed. São Paulo: Abril Cultural, 1978.

7 Tradução livre do original: "In this context, it is possible to speak of a 'methodological nationalism', meaning explicit and implicit assumptions that the nation state is the container of social processes, and that the national provides the core order for the analysis of social, economic and political processes. It is exactly this nation state a priori of the social sciences, which is becoming fundamentally questionable in the course of the pluralisation of borders." BECK, Ulrich. The cosmopolitan state, p. 146. 
tor de todos os processos sociais, políticos, econômicos, bem como - de acordo com a doutrina majoritária no campo da ciência jurídica, cujo grande percursor foi Hans Kelsen - do monopólio de criar, dizer e executar o direito.

Assim, a ordem jurídica resta, constantemente, assimilada como uma ordem institucional estabelecida por uma autoridade soberana, um Estado, sob a ameaça de um poder coercitivo. E, portanto, a construção de um sistema legal e a asserção de uma ordem política soberana vêm sendo, historicamente, compreendidas como dois lados (conhecimento e poder) da mesma moeda real.

Segundo o jurista americano Harold Berman, esse paradigma da vinculação monogâmica entre direito e Estado, que leva à compreensão por demais estreita do direito, "como um conjunto de leis, procedimentos, normas administrativas e técnicas válidas em um determinado país", não subsiste a um estudo histórico da Tradição Jurídica Ocidental.

\begin{abstract}
Para falar da Tradição Jurídica Ocidental, é necessário postular um conceito de Direito que seja diferente de um conjunto de regras, que o veja como um processo, como um empreendimento no qual as regras só têm valor num contexto de instituições e procedimentos, valores e modos de pensar. Desse ponto de vista mais amplo, as fontes do Direito ultrapassam a vontade do legislador, para abranger também a razão e a consciência da comunidade e os seus usos e costumes. ${ }^{10}$
\end{abstract}

Em que pese o surgimento do paradigma de que o direito deva se originar de uma autoridade soberana, ainda consoante Berman, o direito, sempre, existiu, mesmo antes de sua organização e centralização institucional estatal (ubi societas ibi jus). O jurista explica que o direito no ocidente surgiu "de diferentes sistemas jurídicos integrados, em cada um dos quais os vários elementos recebem parte do seu sentido a partir do sistema como um todo" ${ }^{11}$.

8 "Historically, the construction of a legal system and the assertion of a sovereign political order have been the two sides (knowledge and power) of the same royal coin". Tradução livre: "Historicamente, a construção de um sistema legal e a asserção de uma ordem política soberana têm sido dois lados (conhecimento e poder) da mesma moeda real". FRYDMAN, Benoit. A pragmatic approach to global law. p. 5.

9 BERMAN, Harold. Direito e Revolucão: A formação da tradição jurídica ocidental. Trad. Eduardo Takemi Kataoka. São Leopoldo: Editora Uninsinos, 2006. p. 9.

10 BERMAN, Harold. Direito e Revolução, p. 22.

11 Importante esclarecer que, para o autor, a distinção entre oci-
A primeira forma de centralização do direito no mundo ocidental ocorreu no período da Reforma Gregoriana (século XI), da Igreja Católica, que tinha como objetivo "emancipar o clero do controle dos imperadores, reis e senhores feudais, diferenciando, de forma nítida, a Igreja como entidade política e jurídica da política secular" ${ }^{\prime 2}$.

Esse movimento originou o "Novo Direito Canônico" da Igreja Católica, o primeiro sistema jurídico ocidental. A Igreja passou a ser concebida, além de uma organização espiritual e doutrinária, como uma instituição estruturada e dotada de poderes legislativo e jurisdicional ${ }^{13}$.

Como consequência da divisão entre esfera eclesiástica e não eclesiástica, surgiu uma gama de sistemas jurídicos seculares, que conviveram entre si, em harmonia e competição, em uma mesma comunidade. Havia, na Tradição Jurídico Ocidental, portanto, uma dualidade e coexistência de jurisdições, com a marcante característica de pluralidade de jurisdições e sistemas jurídicos:

O pluralismo jurídico originou-se na distinção entre a política
eclesiástica e as políticas seculares. A Igreja declarou a sua
liberdade do controle secular, a sua jurisdição exclusiva em
certas matérias e concorrente em outras. Leigos, apesar de
governados no geral pelo Direito secular, estavam
sujeitos ao Direito eclesiástico e à jurisdição dos
tribunais eclesiásticos no que se referia a questões
sobre casamento e relações familiares, Direito
sucessório, crimes espirituais, relações contratuais
onde a fé era invocada, entre outros assuntos.
Inversamente, o clero, apesar de geralmente ser
regido pelo Direito eclesiástico, estava sujeito
ao Direito secular e às suas cortes, em relação
a certos tipos de crimes, certos tipos de disputas
de propriedades, entre outros. O próprio Direito

dente e oriente não se dá por critérios meramente geográficos, mas, sim, a partir de uma identidade cultural. O ocidente, seria, portanto, os povos ocidentais inspirados nos gregos, romanos e hebreus. BERMAN, Harold. Direito e Revolução, p. 22.

12 BERMAN, Harold. Direito e Revolução, p. 12. Veja-se aqui que o termo "secular" é utilizado em oposição ao termo "eclesiástico". De acordo com o dicionário Michaelis: "8. Relativo aos leigos; laical. 9. Relativo ou pertencente ao Estado, em contraposição ao que se refere ou pertence à Igreja; temporal, civil, mundano".

13 O conceito de jurisdição aqui empregado não é o conceito tradicional como poder estatal, mas, sim, como local de debate, execução e legitimação do direito. Nas palavras de Ralph Michaels, "Jurisdiction in this sense is defined not as the assertion of state power (which, of course, would be exclusive to the state), but rather as 'the locus for debates about community definition, sovereignty, and legitimacy'." MICHAELS, Ralf. The re-state-ment of non-state law: The state, choice of law, and the challenge from global legal pluralism. 2005. Disponível em: <http://scholarship.law.duke.edu/faculty_scholarship/1226>. Acesso em: 28 mar 2016. p. 16. 
secular estava dividido em vários tipos concorrentes, incluindo os Direitos do rei, feudal, senhorial, da cidade e mercantil. A mesma pessoa podia estar sujeita às cortes eclesiásticas em um tipo de causa, à corte do rei em outro, à corte de seu senhor em um terceiro, a uma corte senhorial em um quarto, à corte da cidade em um quinto e a uma corte de mercadores em um sexto. ${ }^{14}$ (Grifou-se)

Também, o professor alemão Lars Viellechner, autor de "Transnationalisierung des Rechts", explica que a Igreja Católica foi a primeira a concretizar a ideia de estado-direito. Ela não apenas adotou a forma de um Estado, mas também o programa da regra jurídica no âmbito de um Estado de direito, no qual os governantes não apenas regulam por meio do direito, mas a ele estão vinculados $^{15}$.

Essa influência do sistema jurídico eclesiástico, não estatal, torna-se, ainda, mais clara quando se atenta para o fato de que, por um longo tempo, inclusive a compreensão da vinculação do rei às suas próprias leis estava diretamente ligada a fundamentos teológicos-jurídicos ${ }^{16}$.

Somente com a posterior centralização da ordem jurídica para a instituição estatal, usurpando esta toda e qualquer jurisdição autônoma, o positivismo-monista retirou do direito a característica e fundamento divino de sacralização da lei, que o Direito Canônico lhe havia concedido $^{17}$, para dar lugar à primazia da política:

\section{BERMAN, Harold. Direito e Revolução, p. 21.}

15 "Die römisch-katholische Kirche stelle die erste Verkörperung der Idee des »law-state« dar. Sie habe nicht nur die Form eines Staates angenommen, sondern auch das Programm einer »rule by law « unter einer »rule of law « verfolgt, wonach die Herrschenden nicht nur vermittels des Rechts regieren, sondern auch selbst daran gebunden sein sollten." VIELLECHNER, Lars. Transnationalisierung des Rechts. Resumo do autor. Disponível em: <http://www.velbrueck-wissenschaft.de/pdf_ausfuehrlich/978-3-942393-67-6.pdf>. p. 2.

16 Como expõe o jurista Antônio Pedro Barbas Homem, “ $A$ compreensão desta vinculação do rei em consciência não pode ser desligada da apresentação dos pecados dos reis por parte da teologia moral. A propósito do segundo mandamento, Martin de Azpilcueta Navarro aborda longamente o problema do cumprimento da palavra dada nos juramentos porque o não cumprimento das promessas constitui pecado. Em especial, cometem um pecado os reis que aprovam lei penal para seu proveito particular e enriquecimento, se dispensarem das leis divinas ou das leis naturais sem justa causa, ou se, sem justa causa, tirarem os bens às pessoas, excepto os ofícios porque é esta a sua natureza." (Grifou-se). HOMEM, António Pedro Barbas. Judex perfectus: função jurisdicional e estatuto judicial em Portugal, 1640-1820. Coimbra, Almedina, 2003. p. 214.

17 De acordo com BERMAN, “(...) todas as revoluções nacionais a partir do século XVI - exceto a Americana - representaram, em parte, uma luta contra a Igreja Católica (na Rússia, contra a Ortodoxa) e todas transferiram grandes parcelas do Direito Canônico pata o Estado nacional, secularizando-as. Assim sendo, deve-se ter
De acordo com esta teoria, a dessacralização da lei, depois de uma fase de transição durante a qual, ainda sim, teve um fundamento religioso, finalmente se transpassou para sua politização. O domínio eclesiástico deu lugar ao "primado da política", transformando o direito em um produto politico. Assim teria surgido o positivismo jurídico, o qual se desvinculou do voluntarismo teológico do final da Idade Média e inverten a validade jurídica para a Natureza e Vontade. (Grifou-se) ${ }^{18}$.

Eis, portanto, que, em que pese a aparente insuperabilidade do paradigma monista de um nacionalismo metodológico, a história e sociologia do direito parecem demonstrar que, a princípio, nem o ato de legislar e nem a administração da justiça competiam, pelo menos não exclusivamente, ao Estado ${ }^{19}$.

Conforme esclarece o sociólogo Eugen Ehrlich, na obra "Fundamentos da sociologia do direito":

muito depois da administração judiciária estatal aparece o direito estatal. Em primeiro lugar, o Estado, naturalmente, produz a sua própria ordem, o direito público, e quando cria ordens, seja de que tipo forem, prescreve sua competência, seu funcionamento, às vezes também seu procedimento. Muito cedo o direito passa a ser redigido por pessoas privadas incumbidas pelo Estado ou então este reconhece o direito já redigido, especialmente compilações de normas, pelos quais os tribunais agem e decidem. ${ }^{20}$

Dessa forma, a despeito do corte traçado a partir do nacionalismo metodológico, o paradigma do estado-centrismo, instaurado com a centralização do poder estatal, segundo o qual o direito é tradicionalmente concebido como prerrogativa essencial do Estado-nação, não

em mente, ao estudar os sistemas jurídicos, eclesiástico e secular que foram criados no final do século XI e princípio do XII sob o impacto da Revolução Papal, que uma grande quantidade de elementos desses sistemas passou para o Direito secular por força das revoluções nacionais. Nesse aspecto, as revoluções nacionais tiveram um caráter internacional”, BERMAN, Harold. Direito e Revolução, p. 36.

18 Tradução livre do original: "Gemäß dieser Theorie ist die Entsakralisierung des Rechts nach einer Übergangsphase, während der das Recht immerhin noch als religiös fundiert gedacht worden war, schließlich in dessen Politisierung umgeschlagen. Die kirchliche Vorherrschaft sei dem 'Primat der Politik' gewichen, das Recht zu einem Produkt der Politik geraten. Damit sei der Rechtspositivismus aufgekommen, der an den theologischen Voluntarismus des Spätmittelalters angeknüpft und die Rechtsgeltung von Natur auf Willen umgestellt habe".VIELLECHNER, Lars. Transnationalisierung des Rechts, p. 6.

19 " [...] no início nem o ato de legislar nem a administração da justiça competem ao Estado. A administração da justiça não tem origem estatal; ela tem suas raízes em épocas pré-estatais". EHRLICH, Eugen. Fundamentos da sociologia do direito. Trad. René Ernani Gertz. Brasília: Editora Universidade de Brasília, 1986. p. 111.

20 EHRLICH, Eugen. Fundamentos da sociologia do direito, pp. 113. 
corresponde à realidade histórica da Tradição Jurídica Ocidental.

Em verdade, as doutrinas baseadas no nacionanlismo metodológico serviram para fundamentar e sustentar o monopólio do direito e da jurisdição por parte do Estado, em um momento em que este necessitou usurpar tais prerrogativas de diversas jurisdições autônomas. E, durante a ascensão e consolidação do Estado como única autoridade formal a requisitar e praticar a prerrogativa de criar, dizer e executar o direito, as teorias sociológicas baseadas no contratualismo-monista mostraram-se suficientes para a ciência jurídica, no que tange à justificação e legitimação do direito e do ordenamento jurídico ${ }^{21}$.

Ocorre que, com a crescente transnacionalização das relações jurídicas, atores não ligados a qualquer autoridade ou grupo político estatal iniciam uma árdua empreitada pelo reconhecimento de seus atos e regras como jurídicos, reivindicando legitimidade e capacidade normativa transnacional, de forma que o positivismo estado-centrista aparenta não mais fornecer uma resposta lógico satisfatória para a ciência jurídica e para os estudiosos desse novo ramo insurgente no direito internacional.

Nesta toada, torna-se necessário o abandono da sinonímia dos conceitos de Estado e Direito e o retorno à Tradição Jurídica Ocidental, a fim de fundamentar a legitimidade de atores não estatais na esfera transnacional e, por conseguinte, possibilitar a qualificação das normas nesse contexto emergentes como direito ${ }^{22}$.

Assim, toma-se aqui o conceito de que a ordem interna das associações e grupos sociais é a primeira forma do direito, de forma que o conteúdo do sistema jurídico decorre, forçosamente, da estrutura das associações e de suas atividades. Logo, conforme preleciona Ehrlich,

$\mathrm{Na}$ medida em que o direito é uma ordem interna de associações sociais, seu conteúdo forçosamente decorre da estrutura das associações e de sua

21 "The predominance of law's institutionalisation in the state during the Nineteenth and Twentieth centuries casts a long shadow over our present attempts to imagine law." ZUMBANSEN, Peer C. Defining the Space of Transnational Law: Legal Theory, Global Governance \& Legal Pluralism. Disponível em: < https://www.wzb.eu/ sites/default/files/u273/zumbansen_2012_defining_the_space_ of_transnational_law_wzb_hu.pdf $>$. Acesso em 23 jun 2016. p. 19. 22 Em importante crítica, Ralph Michaels esclarece que, apesar da suma importância em estabelecer esse novo pluralismo, superando o estado-centrismo; visão esta que será melhor demonstrada no próximo capítulo. atividade. Qualquer mudança na sociedade e na economia ocasiona, por isso, mudanca no direito; e é impossivel modificar os fundamentos juridicos deles, sem que houvesse também uma mudança na economia e na sociedade. Quando as mudanças jurídicas são arbitrárias e tais que a economia não pode adaptar-se a elas, destrói-se sua ordem interna sem que haja um substitutivo. ${ }^{23}$

Partindo dessa concepção de que o direito não é sinônimo de Estado e de que os sistemas jurídicos decorrem de ordens internas de determinadas associações sociais, que evoluem e se modificam ao longo do tempo, compreende-se que a concepção de um direito transnacional somente é possível por meio da quebra do paradigma do estado-centrismo e do positivismo jurídico. Dessa forma, passa-se à apresentação da nova teoria insurgente, do Pluralismo Jurídico Transnacional.

\section{O DiREITO GLobal SEM ESTADO E A TEORIA DO PLURALISMO JURÍDICO TRANSNACIONAL}

A partir da globalização das atividades sociais e econômicas e da transnacionalização de relações, surgem, nas sociedades transnacionais, diversos atores em estruturas globais altamente especializadas que, em meio às suas redes de atividades e funções desvinculadas a qualquer ordenamento jurídico estatal, criam uma identidade global, produzindo o que hoje são chamados os UNO's ("unidentified normative objects").

Conforme restou acima exposto, para o reconhecimento desses objetos normativos como direito, torna-se imprescindível o abandono paradigmal do nacionalismo metodológico, por meio do qual, apenas, o Estado detém a prerrogativa de criar, dizer e aplicar o direito. E, ao contrário do que se possa imaginar, esta sinonímia entre Direito e Estado - construída, mormente, por teorias contratualistas e do positivismo jurídico — não possui qualquer respaldo em uma perspectiva histórico-sociológica do Direito ${ }^{24}$. \begin{tabular}{l}
\hline 23 EHRLICH, Eugen. Fundamentos da sociologia do direito, p. 47. \\
24 "Em outras palavras, pode-se afirmar que o (sub)sistema ju- \\
rídico (co)evolui com racionalidades diferentes (relacionadas a out- \\
ros sistemas sociais), num cenário em que o Estado não representa \\
mais a única esfera donde a normatividade emana. Emerge, assim, \\
uma pluralidade de atores sociais diferenciados em papéis e cul- \\
turas redunda numa pluralidade de fontes normativas e de sujeitos \\
de direitos merecedores de proteção especial (consumidores, refu- \\
giados, hipossuficientes, etc.)." FORNASIER, Mateus de Oliveira; \\
FERREIRA, Luciano Vaz. A regulação das empresas transnacionais \\
entre as ordens jurídicas estatais e não estatais. In: Revista de Direito
\end{tabular} 
Dessa forma, transpõe-se um dos principais argumentos de oposição ao reconhecimento de um direito global, no sentido de que um sistema jurídico global seria inconcebível por não derivar de Estados-nação (direito estatal) ou de tratados internacionais ratificados por meio de relações políticas entre Estados-nações (direito internacional) ${ }^{25}$.

Isso porque é, exatamente, a quebra do paradigma do nacionalismo metodológico e do positivismo jurídico a condição necessária para a concepção do direito transnacional. Assim, torna-se imperioso retornar às teorias pluralistas do direito.

A adoção da Teoria do Pluralismo jurídico para justificação do direito global, porém, deve ser realizada a partir de uma reformulação de suas bases, como explica Gunther Teubner, em seu artigo "Global Bukowina: Legal Pluralism in the World-Society".

No referido estudo, o consagrado jurista demonstra que, em contraposição à visão de Immanuel Kant, para o qual a globalização do direito só é possível por meio da codificação da política internacional ${ }^{26}$, a ideia da Bukowina global de Eugen Ehrlich, demonstra-se em maior conformidade com o que se observa da constituição de um ordenamento jurídico global.

Explica o autor que a Teoria do Pluralismo jurídico deve ser adotada de forma repaginada, para embasar a existência do direito global. De acordo com Teubner, faz-se necessário fundamentar o pluralismo não mais

Internacional UNICEUB. Disponível em: < http://www.publicacoesacademicas.uniceub.br/index.php/rdi/article/view/3303/pdf>. Acesso em: 13 jan. 2016. p. 399.

25 Àqueles que não conseguem superar a ideia de direito atrelada a um nacionalismo metodológico, cumpre apresentar a ressalva lançada por NASSER, segundo o qual, se não presumido o caráter jurídico das regras ou normas transnacionais que constituem o conjunto das normas e instituições, este esse conjunto não será visto como fragmentos de uma ordem jurídica ou uma variedade de ordens jurídicas em um ambiente de pluralismo jurídico, mas, sim, como fragmentação de uma ordem regulatória ou um pluralismo regulatório. NASSER, Salem Hikmat. Direito Global em Pedaços: Fragmentação, Regimes e Pluralismo. Revista de Direito Internacional, Brasília, v. 12, n. 2, 2015 p. 98-126.

26 "For Kant, the globalization of law, a 'transcendental formula of public law', would be the consequence of a legalization of international politics. If the sovereign states were to agree to certain legal principles enshrined in a binding international agreement, a new and just legal order for all mankind could develop (Ibid., 343ff.)." TEUBNER, Gunther. Global Bukowina: Legal Pluralism in the World-Society. In: Global Law Without A State, ed., Dartsmouth, pp. 3-28, 1996. Disponível em: <http://ssrn.com/abstract=896478>. Acesso em: 23 nov. 2015. p. 2. em grupos e comunidades, mas, sim, para discursos e redes de comunicação ${ }^{27}$.

Claramente, o mundo da vida de diferentes grupos e comunidades não é a principal fonte do direito global. Teorias de pluralismo jurídico terão que reformular seus conceitos fundamentais, mudando seu foco de grupos e comunidades para discursos e redes de comunicação (ver Teubner, 1992:. 1456ff). A fonte social do direito global não é o mundo da vida das redes pessoais globalizados, mas o proto-direito de redes especializadas, organizativa e funcional que estão formando uma identidade global, mas fortemente limitado. O novo direito vivo do mundo é alimentado a partir da auto-reprodução contínua de altamente técnica, altamente especializada, muitas vezes formalmente organizadas e bastante restritas, redes globais de natureza económica, cultural, académica ou tecnológica. ${ }^{28}$

A fonte social do direito global, portanto, pode ser encontrada no "proto-direito" de redes especializadas, formalmente organizadas e funcionais, de modo estritamente setorial, em auto reprodução contínua.

Nesse contexto, para o pluralismo jurídico transnacional, não mais as mudanças na sociedade ou em grupos sociais acarretarão a mudança do direito global, mas a mudança nos discursos e nas formas de comunicações de redes especializadas, tais como os discursos, comuni-

27 Apesar de grandes críticas tecidas à teoria de Teubner, Ralph Michaels concorda que o pluralismo jurídico global não mais pode ser embasado a partir da ideia de direito surgido na comunidade. Isso porque, de acordo com o jurista americano, se algo caracteriza a globalização, é a reduzida importância da comunidade. "Arguably, if anything characterizes globalization, it is the reduced importance of community (cf. Fisher 2008). Interactions occur, and laws are made, among dispersed agents who have very little in common. In global commerce, law does not require communities; to the contrary, law makes close community ties dispensable. Closely knit communities are the exception, not the rule, and a theory of law that puts them in the center risks ignoring other laws, created through global chains of law production (Snyder 1999, 2006) or even through the common use of certain documents (Riles 2008b). The grounding of legal pluralism in communities becomes questionable." MICHAELS, Ralph. Global Legal Pluralism, p. 17.

28 Tradução livre do original: "Clearly, the lifeworld of different groups and communities is not the principal source for global law. Theories of legal pluralism will have to reformulate their core concepts shifting their focus from groups and communities to discourses and communicative networks (see Teubner, 1992: 1456ff.). The social source of global law is not the lifeworld of globalized personal networks, but the protolaw of specialized, organisational and functional networks which are forming a global, but sharply limited identity. The new living law of the world is nourished not from stores of tradition but from the ongoing self-reproduction of highly technical, highly specialized, often formally organized and rather narrowly defined, global networks of an economic, cultural, academic or technological nature." TEUBNER, Gunther. Global Bukowina, pp. 4-5. 
cações e inter-relações que originam a lex sportiva ou lex mercatoria transnacional, por exemplo.

Eis, portanto, que, na elaboração desses discursos, surgem novos atores, que se relacionam e se comunicam formando as referidas redes especializadas na esfera transnacional. Assim, os Estados-nação são forçados a se comportarem como coatores, sem divisão hierárquica de papeis.

Nesse sentido, na esfera transnacional, de acordo com Benoit Frydman, em "A Pragmatic Approach to Global Law”, os Estados perdem, de certa forma, sua soberania:

Em um mundo sem um soberano, os Estados são obrigados a se comportar como atores, entre os demais. O Estado, soberano (até certo ponto) no seu próprio território, perde toda a soberania (apesar do que diz o direito internacional público) assim que atravessa fronteiras e deve comprometerse com outras forças. Estas forças são de outros Estados, é claro, mas também de outros tipos de atores da sociedade do mundo, como as organizações internacionais e as organizações nãogovernamentais, ou empresas de transição e suas redes. ${ }^{29}$

Esses novos atores podem ser exemplificados por organizações não governamentais, associações de redes especializadas, movimentos sociais de alcance internacional, empresas transnacionais - entre outros, que possuem não apenas relevância normativa, mas também deslocam a resolução de eventuais conflitos da jurisdição estatal ${ }^{30}$.

29 Tradução livre do original "In a world without a Sovereign, the States are forced to behave as actors among others. The State, sovereign (up until a certain point) within its own territory, loses all sovereignty (despite what international public law says) as soon as it crosses frontiers and must compromise with other forces. These forces are those of other States of course, but also those of other kinds of actors of the world society, such as international organisations and non-governmental organisations, or transitional firms and their networks." FRYDMAN, Benoit. A pragmatic approach to global law, p. 6.

30 "Esses novos atores - que podem, não exaustivamente, ser exemplificados por organizações internacionais governamentais, organizações não governamentais (incluindo movimentos sociais de alcance internacional e empresas transnacionais - possuem não apenas relevância geopolítica: seus poderes podem se espraiar até a normatividade jurídica. [...] Ademais, sequer a resolução de eventuais conflitos advindos dessas cadeias perpassa, compulsoriamente, pela jurisdição tradicional: Cortes e outras instâncias não estatais constituem os meios de resolução de conflitos típicos das relações advindas dessas verdadeiras ordens jurídicas surgidas de cadeias contratuais fomentadas (e criadas) pelas empresas transnacionais." FORNASIER, Mateus de Oliveira; FERREIRA, Luciano Vaz. A regulação das empresas transnacionais entre as ordens jurídicas estatais e não estatais, p. 397.
O pluralismo jurídico é, então, a lente pela qual se deve enxergar o direito global: não mais como uma ordem única de atores soberanos, mas como uma constelação de sistemas jurídicos inter-relacionados ${ }^{31}$. Somente por meio das lentes da Teoria do Pluralismo Jurídico transnacional torna-se possível conceber a existência do direito global ou direito transnacional.

No entanto, cumpre esclarecer que a mera adoção da Teoria do Pluralismo Jurídico transnacional por parte da comunidade acadêmica internacional não tem cunho de embasar completamente a existência do direito transnacional, tornando-se forçoso que se estabeleçam trabalhos interdisciplinares também em relação à filosofia e sociologia do direito.

Isso, porque, apesar do reconhecimento da necessidade de ruptura do paradigma do nacionalismo metodológico, as tentativas de definição e fundamentação de um direito transnacional continuam tomando o Estado como figura central. É dizer, o direito transnacional, ainda, é definido como direito além do Estado, ou direito não estatal; seu conceito tem, no Estado, um critério de referência negativo.

E isto é um dos pontos de crítica de Ralph Michaels, segundo o qual a tendência em contrapor o pluralismo jurídico ao estado-centrismo, reconhecendo o primeiro como mais factível que o segundo (e a ele superior), torna-se uma mera representação da realidade jurídica. De acordo com o autor, enquanto o pluralismo jurídico continuar à margem e à sombra do centralismo jurídico, este não será passível de ser superado ${ }^{32}$.

Eis, portanto, as condições lógicas para a teorização de uma ordem jurídica transnacional, condições estas que ainda se encontram distantes de uma solução palpável e predominantemente aceitável, tal como ocorre com o nacionalismo metodológico. Porém, cabe aqui estudar os avanços traçados pela comunidade acadêmica na tentativa de fundamentação e legitimação do direi-

31 FRYDMAN, Benoit. A pragmatic approach to global law, p. 4.

32 "There is a tendency away from positing legal pluralism as a fact opposed to the fiction of state centralism (Griffiths 1986, p. 4) and toward recognizing that legal pluralism is no more a reality than legal centralism, but rather is merely another (though potentially superior) representation of legal reality (Belley 1997, Kennedy 2007). However, as long as legal pluralism remains the mere flipside of legal centralism, legal centralism will not be overcome." MICHAELS, Ralf. Global Legal Pluralism. Annual Review of Law \& Social Science, Vol. 5, 2009; Duke Law School Public Law \& Legal Theory Research, No. 259, 2009. Disponível em: <http://ssrn. com/abstract $=1430395>$. Acesso em: 20 jan. 2016. p. 23. 
to transnacional, bem como de seus critérios de aferição próprios como sistema jurídico autônomo sui generis.

\section{Direito transnacional e a tentativa DE FORMULAÇÃO DE CRITÉRIOS DE AFERIÇÃO PRÓPRIOS}

Pelo fato de a existência do direito global ou direito transnacional somente ser passível de ser justificada a partir de uma teoria pluralista, seus critérios de averiguação de validade, eficácia e legitimidade não podem estar fundamentados com base nos critérios de aferição dos sistemas jurídicos nacionais.

De acordo com Gunther Teubner, as normas de direito global ou transnacional produzem um ordenamento jurídico sui generis, sobre o qual o jurista formula três importantes teses.

A primeira tese já se encontra apresentada neste trabalho, no sentido de que o direito global só pode ser interpretado por meio de uma Teoria do Pluralismo Jurídico e de uma teoria das fontes também pluralista, concentrada nos processos espontâneos de formação do direito ${ }^{33}$.

Nessa toada, uma Teoria do Direito Global deve focar-se nos processos espontâneos de formação, que, hoje, podem ser encontrados nos discursos das redes especializadas das diversas áreas da sociedade mundial.

33 "Global law can only be adequately explained by a theory of legal pluralism which turned from the law of colonial societies to the laws of diverse ethnic, cultural and religious communities in modern nation-states. It needs to make another turn - from groups to discourses. It should focus its attention on a new body of law that emerges from various globalization processes in multiple sectors of civil society independently of the laws of the nation states." Tradução: "O direito global só pode ser interpretado adequadamente por meio de uma teoria do pluralismo jurídico e de uma teoria das fontes do direito, correspondentemente concebida em termos pluralistas. Somente há pouco tempo a teoria do pluralismo jurídico passou por uma transformação bem-sucedida, deslocando o seu foco do direito das sociedades coloniais para as formas jurídicas de diferentes comunidades étnicas, culturais e religiosas no âmbito do Estado-nação da idade moderna. Hoje em dia ela deveria novamente ajustar o seu foco - do direito dos grupos para o direito dos discursos. Do mesmo modo, uma teoria jurídica das fontes do direito deveria concentrar a sua atenção em processos "espontâneos" de formação do direito que compõem uma nova espécie e se desenvolveram - independentemente do direito instituído pelos Estados individuais ou no plano interestatal - em diversas áreas da sociedade mundial". TEUBNER, Gunther. Global Bukowina, p. 2.
A segunda tese de Teubner sobre o direito global é de que este é um ordenamento sui generis, que não pode ser avaliado de acordo com os critérios de aferição dos sistemas jurídicos nacionais, como os lastreados nos conceitos da sociologia clássica do direito: de norma, sanção e controle social.

O direito global (não: “inter-nacional”!), nesse sentido, é um ordenamento jurídico sui generis que não pode ser avaliado segundo os critérios de aferição de sistemas jurídicos nacionais. Não se trata, como muitos supõem, de um direito atrasado no seu desenvolvimento, apresentando ainda, em comparação com o direito nacional, determinados déficits estruturais. Muito pelo contrário, esse ordenamento jurídico, já amplamente configurado nos dias atuais, distingue-se do direito tradicional dos Estados-nações por determinadas características, que podem ser explicadas por processos de diferenciação no bojo da própria sociedade mundial. Porque, por um lado, se o direito global possui pouco respaldo político e institucional no plano mundial, por outro, ele está estreitamente acoplado a processos sociais e econômicos dos quais recebe os seus impulsos mais essenciais. ${ }^{34}$

No estudo do direito transnacional, os adeptos de uma teoria monista, por vezes, formulam questionamentos tais como: de que forma poderia um direito autêntico emergir espontaneamente em escala transnacional sem a autoridade do Estado, com o seu poder sancionatório ou controle político e sem a legitimação dos processos democráticos? Qual seria a norma fundamentadora do ordenamento jurídico transnacional ${ }^{35}$

Ora, consoante Teubner, responder a esses questionamentos seria aplicar a um direito sui generis a lógica de um direito (interno) que apenas pode ser concebido interna e dependentemente de um Estado-nação, sendo este o pressuposto absoluto para sua criação e implementação.

34 Tradução do original: "The emerging global (not inter-national!) law is a legal order in its own right which should not be measured against the standards of national legal systems. It is not - as is usually understood - an underdeveloped body of law which has certain structural deficiencies in comparison to national law. Rather, its peculiar characteristics as fully fledged law distinguishes it from the traditional law of the nation states. These characteristics can be explained by differentiation within world society itself. While global law lacks political and institutional support on the global level, it is closely coupled with globalized socio-economic processes." TEUBNER, Gunther. Global Bukowina, p. 2.

35 "How can authentic law `spontaneously' emerge on a transnational scale without the authority of the state, without its sanctioning power, without its political control and without the legitimacy of democratic processes? Where is the global Grundnorm (Kelsen, 1960)? Where is the global 'rule of recognition' (Hart, 1961: 92ff.)?” TEUBNER, Gunther. Global Bukowina, p. 7. 
A ideia formal de norma como prescrição jurídica formulada a partir de uma autoridade formalmente instituída de poderes, mediante processo legislativo previamente estipulado e munida de força coercitiva, perde a posição estratégia que ocupa, nas teorias positivistas, como sendo elemento-chave do direito. Os elementos do ordenamento jurídico passam a ser, durante a transformação da "estrutura" em "processo", os eventos comunicativos e atos jurídicos.

Também, a noção de sanção passa a ter relevância secundária, não sendo pressuposto necessário da norma jurídica, mas como apoio simbólico da normatização, sendo irrelevante de onde vem tal apoio simbólico, seja de instituições locais ou nacionais.

Por fim, a terceira tese consiste no fato de que, em que pese se tratar hoje de um direito desvinculado de qualquer política (diferente do direito internacional, por exemplo), o direito transnacional é passível de ser politizado. No entanto, possivelmente, o será por vias pelas quais o direito mundial se acople estruturalmente a discursos especializados, isolados.

\begin{abstract}
A relativa distância à política internacional e ao direito internacional não preservará o "direito mundial sem Estado” de uma repolitização. Muito pelo contrário: justamente a reconstrução de (trans) ações sociais e econômicas como atos jurídicos globais solapa o caráter apolítico do direito global e fornece dessarte o fundamento da sua repolitização. Ela, porém, ocorrerá previsivelmente sob novas formas, pouco conhecidas até agora. Suspeito que o direito mundial não será repolitizado por instituições políticas tradicionais, e.g. de natureza por assim dizer parlamentar, mas justamente pela via daqueles processos nos quais o direito mundial se "acopla estruturalmente" a discursos altamente especializados, isolados. ${ }^{36}$
\end{abstract}

Assim, o direito transnacional identifica uma terceira categoria de ordem jurídica autônoma, além das tradicionais categorias de direito nacional e direito internacional ${ }^{37}$, para a qual não se aplica a lógica jurídica

36 Tradução do original: "Its relative distance from international politics will not protect global law from its re-politicization. On the contrary, the very reconstruction of social and economic (transactions as a global legal process undermines its non-political character and is the basis of its re-politicization. Yet this will occur in new and unexpected ways. We can expect global law to become politicized not via traditional political institutions but within the various processes under which law engages in 'structural coupling' with highly specialized discourses.” TEUBNER, Gunther. Global Bukowina, p. 2. 37 "Transnational law identifies a third category of autonomous legal orders beyond the traditional categories of national and international law. [...]". CALLIES, Peter apud TEUBNER, Gunther. Two tradicional, sendo necessária a construção de uma teoria própria, ainda em fase de formação.

Nesse ato de criação, importante notar qual seria o critério de aferição de legitimidade e validade das normas jurídicas transnacionais, uma vez que, como já mencionado, a elas não se aplicam os mesmos critérios impostos às normas jurídicas estatais.

Em seus estudos acerca do regime transnacional de regulação da internet e o registro de domínios, o professor Lars Viellechner produziu a obra "Transnationalisierung des Rechts", a qual, de forma minuciosa, procura desenvolver critérios específicos de aferição da validade e legitimidade das normas jurídicas transanacionais.

Consoante Viellechner, o direito transnacional deve ser entendido como direitos (1) transfronteiriços, ainda que não se refiram necessariamente a questões globais, (2) tanto às relações de indivíduos como também de objetos regidos pelo interesse comum, pelo qual geralmente se restringem a áreas individuais (Sachbereiche), e (3), predominantemente, mas não exclusivamente, é definido por atores não-estatais em forma de contrato.

Transnationales Rechtistdannals Rechtzuverstehen,
das (1) grenzüberschreitende, wenn auch nicht
notwendigerweise weltumspannende, Sachverhalte
betrifft, (2) sowohl die Beziehungen der Einzelnen
als auch Gegenstände von allgemeinem Interesse
regelt, wobei es sich regelmäßig auf einzelne
Sachbereiche beschränkt, und (3) überwiegend,
wenn auch nicht ausschließlich, durch nicht-
staatliche Akteure in Vertragsform gesetzt wird.
Ergänzt wird es durch allgemeine Rechtsgrundsätze,
welche die meisten Rechtsordnungen enthalten.
Eine relative Unabhängigkeit von anderen
Rechtsordnungen erlangt es durch die Einsetzung
eigener Streitentscheidungsmechanismen (180 f.). ${ }^{38}$

No conceito de fontes do direito transnacional, para Viellechner, estão abarcadas instituições ou associações não estatais que, por meio de contratos transnacionais, se efetuam como atores e para as quais são empregados mecanismos de resolução de conflitos próprios.

Segundo Viellechner, trata-se, principalmente, de um regime transnacional de ordem privada, embora não exclusivamente, posto que, também, acordos híbridos, com elementos de direito público, são por ele alcança-

kinds of legal pluralism: collision of laws in the double fragmentation of world society. 2010. Disponível em: <http://papers.ssrn.com/sol3/ papers.cfm?abstract_id=1416041 >. Acesso em: 4 jan. 2016. p. 9.

38 Tradução livre no parágrafo anterior. TEUBNER, Gunther. Transnationales Recht, p. 3. 
dos — à exceção dos acordos pacíficos de regime de união de Estados, uma vez que estes já se encontram suficientemente abrangidos pelo direito internacional (público) $)^{39}$.

Viellechner defende que a combinação da globalização com a privatização da legislação finalmente quebrou a cadeia de legitimidade do direito baseada no modelo de Constituição de Estado ${ }^{40}$. Assim, as teorias de legitimação do ordenamento normativo transnacional que se baseiem nos exemplos de vontade do mundo estatal estão fadadas ao fracasso.

Também as teorias de legitimação baseadas no consenso contratual, no sentido de que os diversos atores do campo jurídico transnacional, agrupados em redes especializadas, consentem com as normas originadas nos diversos sistemas jurídicos transnacionais, encontram obstáculos.

A fundamentação supramencionada tem grave problema de consolidação em razão da assimetria de poderes entre os envolvidos no campo jurídico transnacional, bem como nos efeitos negativos externalizados a terceiros - indivíduos e instituições. De certo, atores social ou economicamente mais poderosos poderiam impor sua vontade por meio do uso de sua força, em detrimento do consenso e de direitos de atores com pouca representação.

Para tanto, Viellechner encontra a resposta em uma nova compreensão da eficácia horizontal dos direitos fundamentais como fundamento e limite da legislação transnacional ("Horizontalwirkung von Grundrechten als Grund und Grenze transnationaler Rechtssetzung") ${ }^{41}$.

De acordo com a Teoria da "Horizontalwirkung von Grundrechten", a eficácia dos direitos fundamentais não estaria restrita às relações entre Estado e particulares, implicando apenas uma imposição de atitude negativa por parte de terceiros, no sentido de não cometer atos que desrespeitem os direitos particulares dos cidadãos. Mas, sim, em um plano horizontal, de determinar que também as relações inter-privadas, entre particulares, também devem ser regidas com base em uma postura ativa de proteção aos direitos fundamentais.

A proteção dos direitos fundamentais deve ser utilizada quando as tendências expansionistas de regimes jurídicos transnacionais causem perigos

39 TEUBNER, Gunther. Transnationales Recht, p. 3.

40 TEUBNER, Gunther. Transnationales Recht, pp. 4-5.

41 TEUBNER, Gunther. Transnationales Recht, p. 5. a terceiros - pessoas ou instituições. Mas o componente positivo é o de ser reformulada de modo a que os direitos fundamentais também tenham, em seu efeito horizontal, um direito positivo de participação ou, pelo menos, de proteção de interesses. Sob condições de transnacionalidade, isto significa a obrigação de "responsabilidade", portanto, a obrigação de tomar os interesses dos terceiros no cálculo da decisão. ${ }^{42}$

Nesse sentido, por meio da teoria de que, também, as relações particulares devem ser regidas pela eficácia (horizontal) dos direitos fundamentais, a legitimidade e os limites da legislação transnacional encontram-se definidos por tais direitos, a fim de evitar que a assimetria de poderes cause danos a envolvidos, bem como a terceiros, sejam eles indivíduos ou instituições.

Eis, portanto, que o direito transnacional não possui fundamento de legitimidade com base em qualquer ordem estatal ou dependente de seu reconhecimento. Por este esse motivo, a jurisdição transnacional encontra-se, em princípio, em uma relação heterárquica para com os ordenamentos jurídicos estatais e o direito internacional. No âmbito de determinado ordenamento jurídico estatal, porém, eles se estruturam de forma hierárquica, pois geram normas secundárias e até mesmo normas constitucional.

Assim, juntamenteo às normas dos Estados Mundiais, o direito transnacional forma um sistema jurídico global, cuja unidade não é causada pela coerência das normas, mas, sim, pela mera associação de operações jurídicas ${ }^{43}$.

As teorias de legitimação e os critérios de aferição do sistema jurídico transnacional encontram-se em constante evolução e superação de preconceitos consolidados no campo jurídico. Porém, como todo e qualquer recente objeto, a fase de construção demanda uma árdua empreitada por parte de juristas, filósofos e sociólogos do direito, cujos trabalhos devem transpor as dúvidas científicas, por meio de uma nova lente de visão.

42 Tradução livre do original: „Grundrechtsschutz muss dann einsetzen, wenn expansive Tendenzen transnationaler Rechtsregimes Gefährdungen Dritter - Individuen wie Institutionen auslösen (218 ff.). Aber auch die positive Komponente ist neu zu fassen, so dass Grundrechte auch in ihrer Horizontalwirkung einen positiven Anspruch auf Teilhabe oder jedenfalls Interessenberücksichtigung geben. Unter Bedingungen der Transnationalität bedeutet dies eine Pflicht zur „Responsivität“, also die Pflicht, die Interessen Drittbetroffener in das Entscheidungskalkül aufzunehmen (221 ff.).” TEUBNER, Gunther. Transnationales Recht, p. 5.

43 TEUBNER, Gunther. Transnationales Recht, pp. 6-7. 


\section{Considerações finais}

No contexto transnacional, diferentes atores do mundo globalizado, estruturados em associações e redes especializadas de discursos, dão vida a uma incontável quantidade de objetos normativos (ainda) não identificados, denominados de "UNO's" ("unidentified normative objects").

Para o reconhecimento desses UNO's como direito, torna-se imprescindível quebrar o paradigma monista do nacionalismo metodológico, por meio do qual apenas o Estado detém a prerrogativa de criar, dizer e aplicar o direito. E, conforme demonstrado a partir da análise da Tradição Jurídica Ocidental, esta essa sinonímia entre Direito e Estado - construída, mormente, por teorias contratualistas - não possui qualquer respaldo em uma perspectiva histórico-sociológica do Direito.

O pluralismo jurídico é, então, a lente pela qual se deve enxergar o direito global: não mais como uma ordem única de atores soberanos, mas como uma constelação de sistemas jurídicos inter-relacionados.

Somente, através por meio das lentes da Tteoria do Ppluralismo Jjurídico Ttransnacional, torna-se possível conceber a existência do direito global ou direito transnacional, que emerge partir de discursos e redes de comunicação especializadas, formalmente organizadas e funcionais, de modo estritamente setorial, em autorreprodução contínua, em esferas de abrangência transnacional.

Nesse contexto, de acordo com o jurista Lars Vellechner, o direito trasnacional deve ser entendido como direitos (1) transfronteiriços, ainda que não se refiram necessariamente a questões globais, (2) tanto às relações de indivíduos como também de objetos regidos pelo interesse comum, pelo qual geralmente se restringem a áreas individuais (Sachbereiche), e (3), predominantemente, mas não exclusivamente, é definido por atores não -estatais em forma de contrato.

Essas normas jurídicas transnacionais produzem um ordenamento jurídico sui generis, que não pode ser avaliado de acordo com os critérios de aferição dos sistemas jurídicos nacionais, como os lastreados nos conceitos da sociologia clássica do direito: de norma, sanção e controle social.

Assim, as teorias de legitimação do ordenamento normativo transnacional que se baseiem nos exemplos de vontade do mundo estatal estão fadadas ao fracasso, devendo o direito transnacional buscar seus critérios de aferição de validade e legitimidade próprios.

Adota-se, então, a tese de Lars Viellechner, para o qual a legitimidade e os limites da legislação transnacional encontram-se definidos pela eficácia horizontal dos direitos fundamentais, segundo a qual, também, os particulares, em suas inter-relações, devem manter uma postura ativa de proteção aos direitos fundamentais.

Eis, portanto, que o direito transnacional não possui fundamento de legitimidade com base em qualquer ordem estatal ou dependente de seu reconhecimento. Por esse motivo, a jurisdição transnacional encontra-se, em princípio, em uma relação heterárquica para com os ordenamentos jurídicos estatais e o direito internacional.

O direito transnacional, junto às normas dos Estados Mundiais, forma um sistema jurídico global, cuja unidade não é causada pela coerência das normas, mas, sim, pela mera associação de operações jurídicas.

Conforme se demonstrou, as teorias de legitimação do direito transnacional não podem se usurpar da racionalidade lógica aplicada ao direito estatal, regido pelo paradigma do nacionalismo metodológico. Assim, torna-se necessário que o pluralismo jurídico transnacional supere a visão do Estado como ponto central, a fim de evitar estar à margem e à sombra do centralismo jurídico.

Tais teorias encontram-se em constante evolução e superação de preconceitos consolidados no campo jurídico. Como todo e qualquer objeto relativamente novo, a presente fase de construção e autonomia do direito transnacional demanda uma árdua empreitada por parte de juristas, filósofos e sociólogos do direito, cujos trabalhos devem transpor as dúvidas científicas, por meio de uma nova lente de visão.

Espera-se daqueles que venham a ser introduzidos a esse novo sistema jurídico uma postura de abertura de conhecimento, sem a qual não é possível superar antigos e ultrapassados paradigmas.

\section{REFERÊNCIAS BIBLIOGRÁFICAS}

BECK, Ulrich. The cosmopolitan state: redefining power in the global age. Disponível em: <https:// equilibrium0.files.wordpress.com/2011/05/beck2006. 
pdf>. Acesso em: 26 jan. 2016.

BERMAN, Harold. Direito e Revolução: A formação da tradição jurídica ocidental. Trad. Eduardo Takemi Kataoka. São Leopoldo: Editora Uninsinos, 2006.

EHRLICH, Eugen. Fundamentos da sociologia do direito. Trad. René Ernani Gertz. Brasília: Editora Universidade de Brasília, 1986.

FORNASIER, Mateus de Oliveira; FERREIRA, Luciano Vaz. A regulação das empresas transnacionais entre as ordens jurídicas estatais e não estatais. In: Revista de Direito Internacional UNICEUB. Disponível em: <http://www.publicacoesacademicas. uniceub.br/index.php/rdi/article/view/3303/pdf > . Acesso em: 13 jan. 2016.

FRYDMAN, Benoit. A pragmatic approach to global law. 2013. Disponível em: <http://ssrn.com/abstract $=2312504>$. Acesso em: 13 jan. 2016.

HOMEM, António Pedro Barbas. Judex perfectus: função jurisdicional e estatuto judicial em Portugal, 1640-1820. Coimbra: Almedina, 2003.

LOCKE, John. Segundo tratado sobre o governo. In: Carta acerca tolerância; Segundo tratado sobre o governo; Ensaio acerca do entendimento humano. 2. ed. São Paulo: Abril Cultural, 1978.

MICHAELS, Ralf. Global Legal Pluralism. Annual Review of Law \& Social Science, Vol. 5, 2009; Duke Law School Public Law \& Legal Theory Research, No. 259, 2009. Disponível em: <http://ssrn.com/abstract $=1430395>$. Acesso em: 20 jan. 2016.

The re-state-ment of non-state law: The state, choice of law, and the challenge from global legal pluralism. 2005. Disponível em: < http://scholarship. law.duke.edu/faculty_scholarship/1226>. Acesso em: 28 mar 2016.

NASSER, Salem Hikmat. Direito Global em Pedaços: Fragmentação, Regimes e Pluralismo. Revista de Direito Internacional, Brasília, v. 12, n. 2, 2015 p. 98-126.

TEUBNER, Gunther. Bukowina global sobre a emergência de um pluralismo jurídico transnacional. Direito e Globalização 14, 2003. Disponível em: <http://www.unimep.br/phpg/editora/revistaspdf/ imp33art01.pdf>. Acesso em: 23 nov. 2015

Global Bukowina: Legal Pluralism in the World-Society. In: Global Law Without A State, ed., Dartsmouth, pp. 3-28, 1996. Disponível em: $<$ http://ssrn.com/abstract $=896478>$. Acesso em: 23 nov. 2015.

Transnationales Recht: Legitimation durch horizontale Grundrechtswirkung. 2015. Disponível em: $<$ https://www.jura.uni-frankfurt.de/53908273/ViellechnerRezension1.pdf>. Acesso em: 4 jan. 2016.

Two kinds of legal pluralism: collision of laws in the double fragmentation of world society. 2010. Disponível em: <http://papers.ssrn.com/sol3/papers. cfm?abstract_id=1416041>. Acesso em: 4 jan. 2016.

VIELLECHNER, Lars. Transnationalisierung des Rechts. Resumo do autor. Disponível em: <http:// www.velbrueck-wissenschaft.de/pdf_ausfuehrlich/978-3-942393-67-6.pdf>. Acesso em: 12 jan. 2016.

ZUMBANSEN, Peer C. Defining the Space of Transnational Law: Legal Theory, Global Governance \& Legal Pluralism. Disponível em: https://www.wzb.eu/ sites/default/files/u273/zumbansen_2012_defining_ the_space_of_transnational_law_wzb_hu.pdf $>$. Acesso em 23 jun 2016. 
Para publicar na Revista de Direito Internacional, acesse o endereço eletrônico www.rdi.uniceub.br ou www.brazilianjournal.org.

Observe as normas de publicação, para facilitar e agilizar o trabalho de edição. 